\title{
Analisis Sebaran Jaringan Penakar Hujan Dengan Metode Stepwise, Kriging \& WMO Di DAS Serang Jawa Tengah
}

\author{
Analysis of Rain Gauge Station Distribution with Stepwise, Kriging \& WMO \\ Methods in Serang Watershed, Central Java
}

\author{
Oksa Ega Hermawan ${ }^{1}$, Lily Montarcih Limantara ${ }^{1}$, Ery Suhartanto ${ }^{\left.{ }^{*}\right)}$ \\ ${ }^{1}$ Jurusan Teknik Pengairan, Fakultas Teknik, Universitas Brawijaya, Malang, Indonesia
}

Article info:
Kata kunci:
metode Kriging, metode Stepwise,
standar WMO

Keywords:

Kriging method, Stepwise method, WMO standard

\section{Article history:}

Received: 08-07-2020

Accepted: 29-11-2020

${ }^{*}$ Koresponden email: egaoxa@gmail.com

\begin{abstract}
Abstrak
DAS Serang merupakan salah satu Daerah Aliran Sungai yang berada di Jawa Tengah dan memiliki luas sekitar $3648 \mathrm{~km}^{2}$. Hasil analisis sebaran pos hujan pada DAS Serang menggunakan metode Stepwise dan Kriging menunjukkan sebaran sudah bagus, hal ini ditunjukkan pada metode Stepwise dengan nilai R (koefisien antar variabel) mendekati angka 1 yang berarti hubungan antar stasiun kuat dan hasil RMSE pada analisis Kriging yang kecil. Namun jika ditinjau dari standar WMO (World Meteorological Oganization) luas daerah pengaruh pada tiap-tiap stasiun tidak memenuhi standar. Akhirnya dilakukan analisis Rekomendasi I (tujuh stasiun) dan Rekomendasi II (enam stasiun) dengan upaya menghilangkan stasiun-stasiun dengan luas daerah pengaruh terkecil agar memenuhi standar WMO. Namun penghilangan stasiun tidak dianjurkan dikarenakan stasiun hujan merupakan aset negara yang berharga, maka dilakukan upaya Rekomendasi III (sembilan stasiun) dengan menggeser stasiun-stasiun yang sudah ada tanpa ada penghilangan stasiun sehingga luas daerah pengaruh antar stasiun eksisting memenuhi standar WMO.
\end{abstract}

\begin{abstract}
Serang Watershed is one of the river basins in Central Java and has an area of around $3648 \mathrm{~km}^{2}$. The results of rainfall distribution analysis in Serang watershed using Stepwise and Kriging methods show that the distribution is good, which is shown in Stepwise method with value of $\mathrm{R}$ (coefficient among variables) approach 1 , which means relationship among stations is strong and RMSE results in Kriging analysis are small. However, in terms of WMO (World Meteorological Organization) standard, the area of influence at each station does not meet the standards. Finally, analysis of Recommendation I (tujuh stations) and Recommendation II (six stations) was made with efforts to eliminate stations with the smallest area of influence to meet WMO standards, but removal of stations is not recommended because rain stations are valuable assets of the country, so Recommendation III (nine stations) were made to shift existing stations without eliminating stations so that the area of influence among existing stations met WMO standards.
\end{abstract}

Kutipan: Hermawan, O. E., Limantara, L. M., Suhartanto, E. (2020). Analisis Sebaran Jaringan Penakar Hujan Dengan Metode Stepwise, Kriging \& WMO Di DAS Serang Jawa Tengah. Jurnal Teknik Pengairan. https://doi.org/10.21776/ub.pengairan.2020.011.02.07

\section{Pendahuluan}

DAS Serang merupakan salah satu DAS prioritas dalam rencana pembangunan jangka menengah semenjak tahun 2014. Banyak sekali infrastruktur keairan yang berperan penting dalam pembangunan tersebut, salah satunya adalah pos hidrologi. Dalam kegiatan analisis, hidrologi data 
hujan merupakan masukan utama dalam penyediaan informasi. Keakuratan data hujan dipengaruhi oleh jumlah dan pola penempatan pos hujan. Untuk mendapatkan data tersebut, dibutuhkan jaringan pos hidrologi dalam memantau karakteristik hidrologi suatu daerah aliran sungai (DAS).

Adapun beberapa penelitian terdahulu yang mengaitkan hubungan antara kerapatan jaringan pos hujan dan debit aliran pada sungai. Informasi mengenai curah hujan merupakan syarat utama dari semua pemodelan peramalan banjir. Hal ini penting untuk mengetahui pos hujan yang mampu meramalkan banjir dengan akurasi yang diinginkan (Kar et al. 2015). Kerapatan jaringan pos hujan dan pola areal serta distribusi curah hujan dapat mempengaruhi hasil kalibrasi dan validasi pemodelan distribusi curah hujan dengan limpasan (Montesarchio et al. 2015). Selain itu terdapat pula peningkatan pada pendekatan peramalan aliran sungai menggunakan input berbasis jaringan pos hujan yang optimal dengan model jaringan saraf tiruan (Adhikary, Muttil, and Yilmaz 2018). Ketepatan prediksi aliran sungai dari suatu pemodelan hidrologi sangat bergantung pada ketepatan input presipitasi (Gourley and Vieux 2005). Evaluasi jaringan pos hujan juga dapat dilakukan dengan pemodelan hidrologi yang membandingkan debit simulasi dari suatu metode interpolasi dan kerapatan yang sesuai terhadap debit simulasi data curah hujan referensi (Andiego et al. 2018). Untuk mendekati fenomena hidrologi pada daerah aliran sungai yang sukar maka perlu dikembangkan suatu analisis sistem hidrologi dengan menggunakan model yang merupakan penyederhanaan kenyataan alam yang sebenarnya (Hadihardaja and Sutikno 2005).

Tujuan dari studi ini untuk mengevaluasi stasiun hujan eksisting pada DAS Serang dan merencanakan tata letak stasiun hujan yang baru agar dapat mewakili jumlah stasiun hujan yang ada sebelumnya. Stasiun hujan yang baru (rekomendasi) harus memenuhi standar WMO (World Meteorological Organization).

\section{Bahan dan Metode}

\subsection{Lokasi studi}

Lokasi studi berada di DAS Serang yang berada di wilayah sungai Jratunseluna dengan kode Ws 02.14.A3 sebagaimana peta lampiran v.64 menurut kepres nomor 12 tahun 2012 tentang wilayah sungai, yang dapat dilihat pada Gambar 1 .

\subsection{Tahapan penyelesaian}

Dalam penyelesaian penelitian ini sehingga mencapai maksud dan tujuan yang diharapkan, maka berikut ini adalah langkah-langkah penyelesaian studi:

1. Mengumpulkan data (data curah hujan, data debit, data survei dan peta yang diperlukan).

2. Uji konsistensi data debit dan hujan dengan Analisis kurva masa ganda.

3. Penyaringan data hujan dan data debit dengan metode RAPS (Rescaled Adjusted Partial Sums).

4. Analisis curah hujan rerata daerah. Curah hujan yang diperlukan untuk penyusunan suatu rancangan pengendalian banjir adalah curah hujan rata-rata di seluruh daerah yang bersangkutan, bukan curah hujan pada suatu titik tertentu. Curah hujan ini disebut curah hujan daerah yang dinyatakan dalam satuan milimeter (Takeda and Sosrodarsono 2003) dengan metode Polygon Thiessen.

5. Analisis sebaran dan kerapatan Stasiun Hujan serta Pos Duga Air dengan Metode Stepwise menggunakan aplikasi SPSS 21.

6. Analisis sebaran dan kerapatan jaringan stasiun hujan metode Kriging menggunakan aplikasi ArcGIS 10 (pada kondisi eksiting).

7. Perbandingan kesesuaian pola sebaran stasiun hujan pada metode Stepwise dengan Kriging.

8. Analisis kerapatan stasiun hujan rekomendasi (berdasarkan standar WMO). 


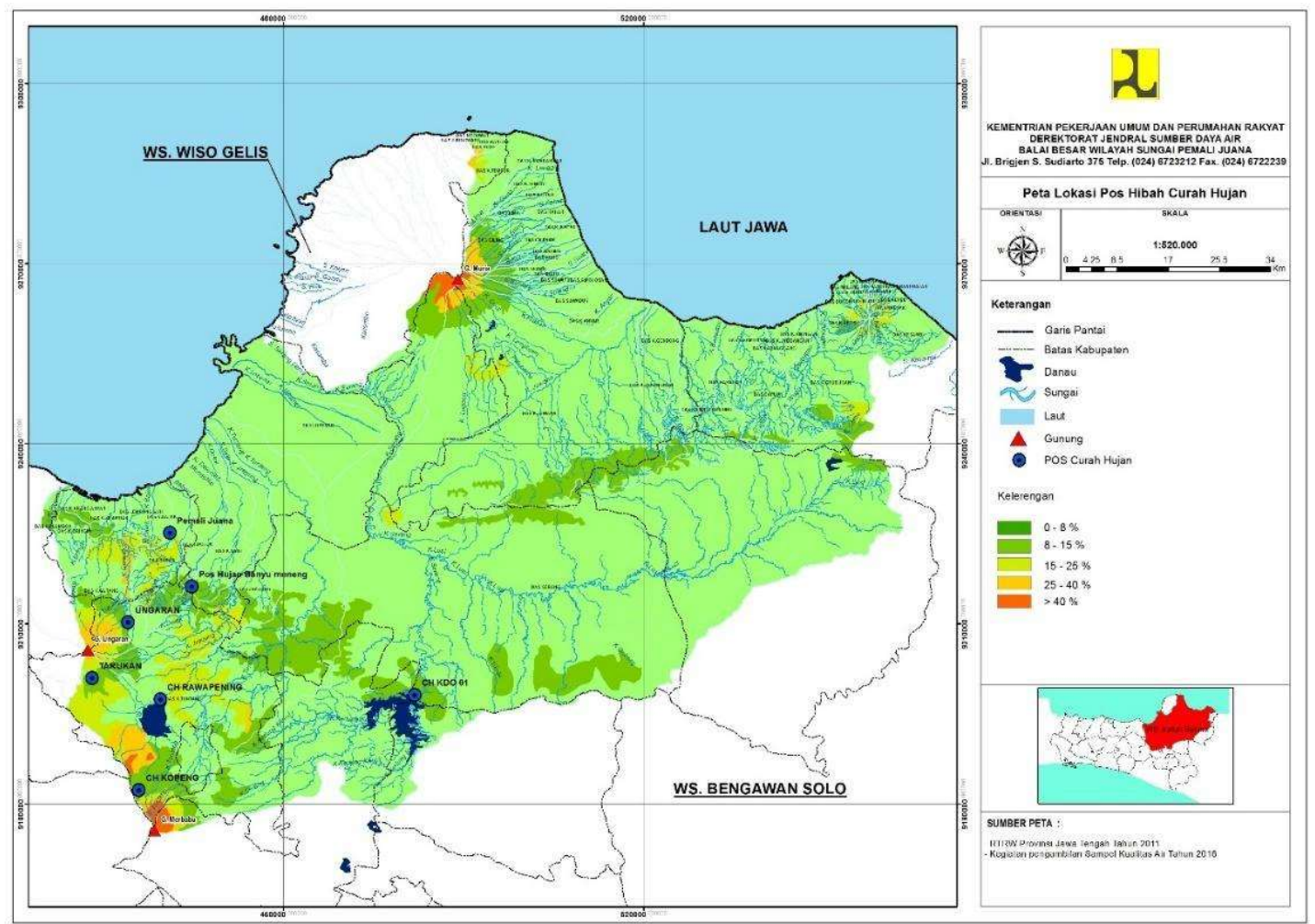

Gambar 1. Peta wilayah Sungai Jratunseluna Sumber: BBWS Pamali Juwana

\section{Hasil dan Pembahasan}

Analisa Stepwise dilakukan dengan memodelkan hubungan antara variabel bebas (stasiun hujan) dengan variabel terikat (stasiun debit). Data yang digunakan adalah data kumulatif tahunan dari setiap hujan dan debit.

Tabel 1. Kriteria penilaian korelasi

\begin{tabular}{cc}
\hline Interval Koefisien & Tingkat Hubungan \\
\hline $0.00-0.199$ & Sangat Rendah \\
\hline $0.20-0.399$ & Rendah \\
\hline $0.40-0.599$ & Sedang \\
\hline $0.60-0.799$ & Kuat \\
\hline $0.80-1.000$ & Sangat Kuat \\
\hline
\end{tabular}

Sumber: Sugiyono (2003:216)

Pada Tabel 1 dapat diketahui bahwa nilai koefisien semakin mendekati angka 1 maka tingkat hubungan antar stasiun yang diuji akan semakin tinggi, begitu juga sebaliknya. Sedangkan pada Tabel 2 dapat diketahui bahwa dari hasil analisis menggunakan metode Stepwise, hubungan antar stasiun hujan T1 sampai dengan T9 sudah menunjukkan tingkat hubungan yang sangat kuat. Dan dapat disimpulkan bahwa semakin banyak variabel bebas yang terkait maka nilai koefisiennya akan semakin mendekati angka 1 yang menunjukkan korelasi yang sangat kuat.

Pada Gambar 2 dapat dilihat bahwa dari hasil analisis didapatkan hasil tiga stasiun hujan yaitu St. Mojoagung, St. Kunthi dan St. Bd. Sidorejo memiliki nilai korelasi yang sangat kuat dengan nilai R 0.824 (mengacu pada Tabel 2). 
Tabel 2. Korelasi Metode Stepwise sederhana dan berganda Pos AWLR Karanganyar dengan Stasiun Hujan di DAS Serang

\begin{tabular}{|c|c|c|c|c|c|c|c|c|}
\hline \multirow[b]{2}{*}{ No } & \multicolumn{4}{|c|}{ Sederhana } & \multicolumn{2}{|l|}{ Berganda } & \multirow[b]{2}{*}{$\begin{array}{c}\text { tingkat } \\
\text { hubungan }\end{array}$} & \multirow[b]{2}{*}{$\begin{array}{c}\text { Kontribusi } \\
(\%)\end{array}$} \\
\hline & $\begin{array}{l}\text { independen } \\
\text { variable }\end{array}$ & $\mathrm{R}$ & $\begin{array}{c}\text { tingkat } \\
\text { hubungan }\end{array}$ & $\begin{array}{c}\text { Kontribusi } \\
(\%)\end{array}$ & independen variable & $\mathrm{R}$ & & \\
\hline 1 & Sidorejo (T1) & 0.065 & $\begin{array}{l}\text { sangat } \\
\text { rendah }\end{array}$ & 0.42 & $\mathrm{~T} 1$ & 0.065 & $\begin{array}{l}\text { sangat } \\
\text { rendah }\end{array}$ & 0.42 \\
\hline 2 & Kunti (T2) & 0.743 & sedang & 55.18 & $\mathrm{~T} 1, \mathrm{~T} 2$ & 0.767 & kuat & 58.82 \\
\hline 3 & Mojoagung (T3) & 0.547 & rendah & 29.89 & $\mathrm{~T} 1, \mathrm{~T} 2, \mathrm{~T} 3$ & 0.824 & $\begin{array}{c}\text { sangat } \\
\text { kuat }\end{array}$ & 67.82 \\
\hline 4 & Susukan (T4) & 0.275 & $\begin{array}{l}\text { sangat } \\
\text { rendah }\end{array}$ & 7.55 & $\mathrm{~T} 1, \mathrm{~T} 2, \mathrm{~T} 3, \mathrm{~T} 4$ & 0.83 & $\begin{array}{c}\text { sangat } \\
\text { kuat }\end{array}$ & 68.87 \\
\hline 5 & $\begin{array}{l}\text { Bd. Wilalung } \\
\text { (T5) }\end{array}$ & 0.274 & $\begin{array}{l}\text { sangat } \\
\text { rendah }\end{array}$ & 7.51 & $\mathrm{~T} 1, \mathrm{~T} 2, \mathrm{~T} 3, \mathrm{~T} 4, \mathrm{~T} 5$ & 0.927 & $\begin{array}{c}\text { sangat } \\
\text { kuat }\end{array}$ & 85.86 \\
\hline 6 & $\begin{array}{l}\text { Mulan Mijen } \\
\text { (T6) }\end{array}$ & 0.531 & rendah & 28.23 & $\mathrm{~T} 1, \mathrm{~T} 2, \mathrm{~T} 3, \mathrm{~T} 4, \mathrm{~T} 5, \mathrm{~T} 6$ & 0.948 & $\begin{array}{l}\text { sangat } \\
\text { kuat }\end{array}$ & 89.94 \\
\hline 7 & Bd. Sedadi (T7) & 0.175 & $\begin{array}{l}\text { sangat } \\
\text { rendah }\end{array}$ & 3.06 & $\begin{array}{l}\text { T1,T2,T3,T4,T5,T6, } \\
\text { T7 }\end{array}$ & 0.963 & $\begin{array}{c}\text { sangat } \\
\text { kuat }\end{array}$ & 92.71 \\
\hline 8 & Wd. Simo (T8 & 0.123 & $\begin{array}{l}\text { sangat } \\
\text { rendah }\end{array}$ & 1.52 & $\begin{array}{l}\text { T1,T2,T3,T4,T5,T6, } \\
\text { T7,T8 }\end{array}$ & 0.967 & $\begin{array}{c}\text { sangat } \\
\text { kuat }\end{array}$ & 93.56 \\
\hline 9 & $\begin{array}{l}\text { Wonosegoro } \\
\text { (T9) }\end{array}$ & 0.647 & sedang & 41.91 & $\begin{array}{l}\text { T1,T2,T3,T4,T5,T6, } \\
\text { T7,T8,T9 }\end{array}$ & 0.967 & $\begin{array}{l}\text { sangat } \\
\text { kuat }\end{array}$ & 93.58 \\
\hline
\end{tabular}

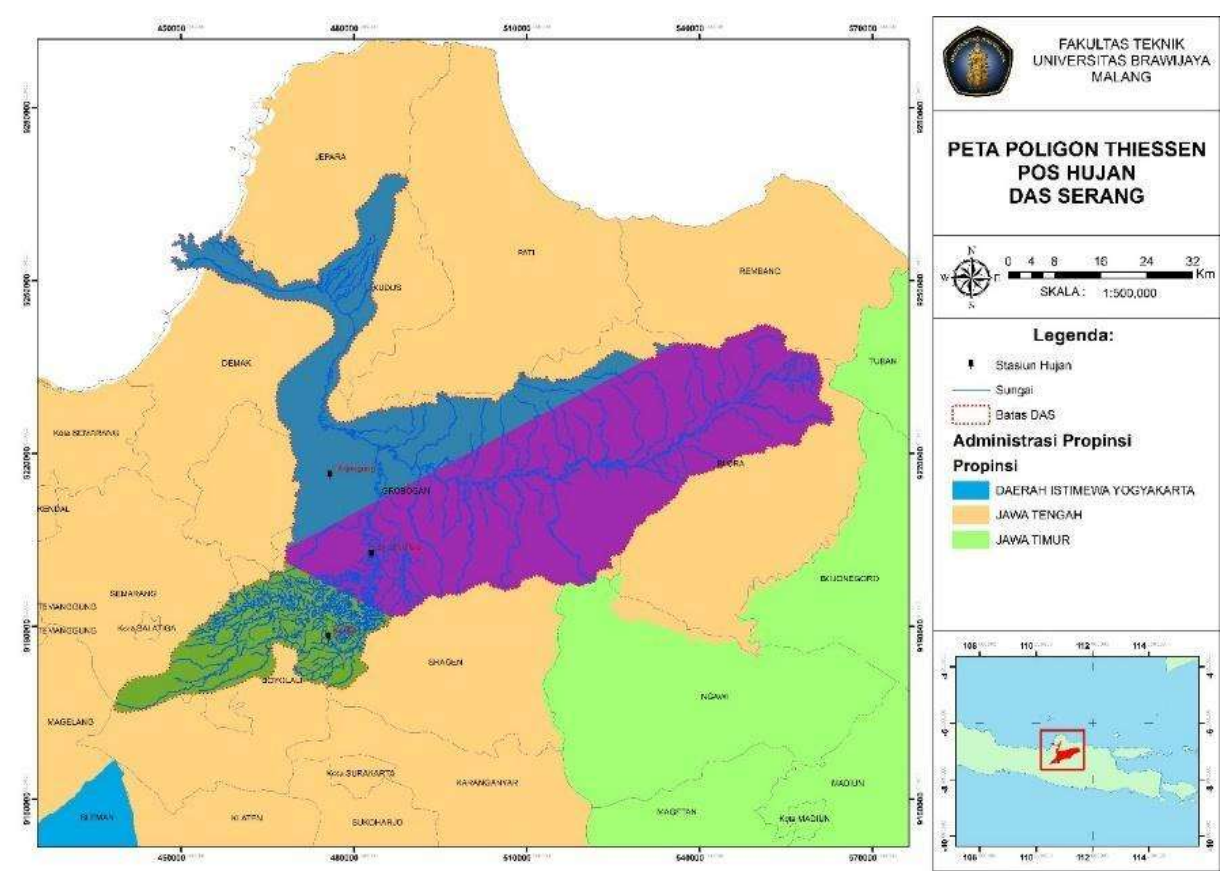

Gambar 2. Peta Polygon Thiessen stasiun hujan DAS Serang dengan Metode Stepwise berdasarkan Pedoman Rasionalisasi Pos Hidrologi Kementerian Pekerjaan Umum

\subsection{Analisa jaringan stasiun hujan dengan Metode Kriging}

Metode ini merupakan asumsi yang dikembangkan oleh Matheron (1965) yang menekankan bahwa interpolasi data dari satu titik terukur ke titik lain dalam suatu DAS yang tidak hanya ditentukan oleh jarak akan tetapi ditentukan oleh tiga faktor lainnya (Sri Harto1993).

Dalam perencanaan jaringan pos hujan dengan metode Kriging didasarkan pada curah hujan tahunan rata-rata tiap pos hujan yang kemudian data tersebut dilakukan permodelan semivariogram. Ada tiga semivariogram yang dipakai dalam studi ini yaitu Spherical, Exponential dan Gaussian. Pada Tabel 3 dapat dilihat hasil pengelolaan data input dari ketiga permodelan. 
Tabel 3. Perbandingan hasil cross validation

\begin{tabular}{ccc}
\hline Model Semivariogram & RMSE & MAE \\
\hline Spherical & 14.342 & 12.352 \\
\hline Exponential & 14.738 & 12.934 \\
\hline Gaussian & 14.397 & 12.551 \\
\hline
\end{tabular}

Berdasarkan Tabel 3, dapat dilihat bahwa model variogram Spherical mempunyai nilai RMSE paling kecil, sehingga dapat disimpulkan bahwa korelasi spasial curah hujan di DAS Serang dapat dijelaskan oleh model semivariogram Spherical.

\subsection{Perhitungan luas daerah pengaruh (rekomendasi)}

Dalam penelitian ini, perhitungan luas daerah pengaruh menggunakan Polygon Thiessen, karena metode ini memplotkan bobot tersendiri pada setiap pos hujan, dengan anggapan tiap-tiap pos hujan mewakili hujan pada satu daerah dengan luasan tersendiri dan luasan itu adalah faktor koreksi (weighting factor) pada setiap hujan di pos yang terkait.

Berdasarkan kriteria yang diberikan oleh WMO (World Meteorological Organization), luas daerah $\left(\mathrm{km}^{2}\right)$ per satu pos hujan diperlihatkan pada Tabel 4. Dari tabel tersebut dapat diketahui bahwa Indonesia masuk pada tipe nomer 2, yaitu daerah pegunungan tropis mediteran sedang dengan luas daerah per satu pos hujan mencakup antara $300-1000 \mathrm{~km}^{2}$.

Tabel 4. Tipe daerah dan jumlah pos hujan yang memenuhi standar WMO

\begin{tabular}{llcc}
\hline \multirow{2}{*}{ No } & \multicolumn{1}{c}{ Tipe } & \multicolumn{2}{c}{ Luas Daerah $\left(\mathrm{km}^{2}\right)$ per satu pos hujan } \\
\cline { 3 - 4 } 1 & $\begin{array}{l}\text { Daerah dataran tropis mediteran } \\
\text { dan sedang }\end{array}$ & $\begin{array}{c}1000-2500 \\
(600-900)\end{array}$ & \multirow{2}{*}{$3000-9000$} \\
\hline \multirow{2}{*}{2} & $\begin{array}{l}\text { Daerah pegunungan tropis } \\
\text { mediteran dan sedang }\end{array}$ & $\begin{array}{c}300-1000 \\
(100-250)\end{array}$ & $1000-5000$ \\
\hline \multirow{2}{*}{3} & $\begin{array}{l}\text { Daerah kepulauan kecil bergunung } \\
\text { dengan curah hujan bervariasi }\end{array}$ & $140-300(25)$ & - \\
\hline 4 & Daerah arid dan kutub & $\begin{array}{c}5000-20000 \\
(1500-10000)\end{array}$ & \\
\hline
\end{tabular}

Sumber: (Triatmodjo 2010)

Gambar 3 menampilkan layout stasiun hujan eksisting pada DAS Serang dengan jumlah stasiun hujan sembilan pos yang tersebar dan sudah dipetakan luas cakupannya menggunakan metode Polygon Thiessen. Pada gambar tersebut dapat dilihat bahwa sebaran stasiun masih kurang merata dengan ditandainya besaran luas daerah cakupan yang kurang merata. Warna-warna pada peta mewakili daerah cakupan tiap-tiap pos hujan yang menyebar di DAS Serang.

Dari Tabel 5 yang merupakan hasil Analisa dari Gambar 3, dapat dilihat bahwa hanya dua stasiun yang luas daerahnya memenuhi kriteria WMO, sedangkan tujuh stasiun lainnya tidak memenuhi standar tersebut (standar WMO satu pos hujan mewakili $300-1000 \mathrm{~km}^{2}$ ).

Setelah melakukan analisa, diperoleh tiga alternatif rekomendasi yang dapat digunakan pada lokasi daerah studi, seperti yang diperlihatkan oleh Gambar 4, Gambar 5 dan Gambar 6, dengan luas daerah pengaruh stasiun hujan pada DAS Serang pada Tabel 6, Tabel 7 dan Tabel 8 secara berturutturut.

Rekomendasi I ditunjukkan pada Gambar 4, di mana stasiun yang luas daerahnya tidak memenuhi kriteria WMO dihilangkan sehingga jumlah stasiun yang awalnya terdapat sembilan stasiun hanya mejadi tujuh stasiun saja. Dari Tabel 6 yang bersesuai dengan perhitungan untuk Gambar 4, diperlihatkan bahwa dua stasiun eksisting yang luas daerahnya tidak memenuhi kriteria WMO (St. Wonosegoro \& St. Bd. Sedadi) dihilangkan. 


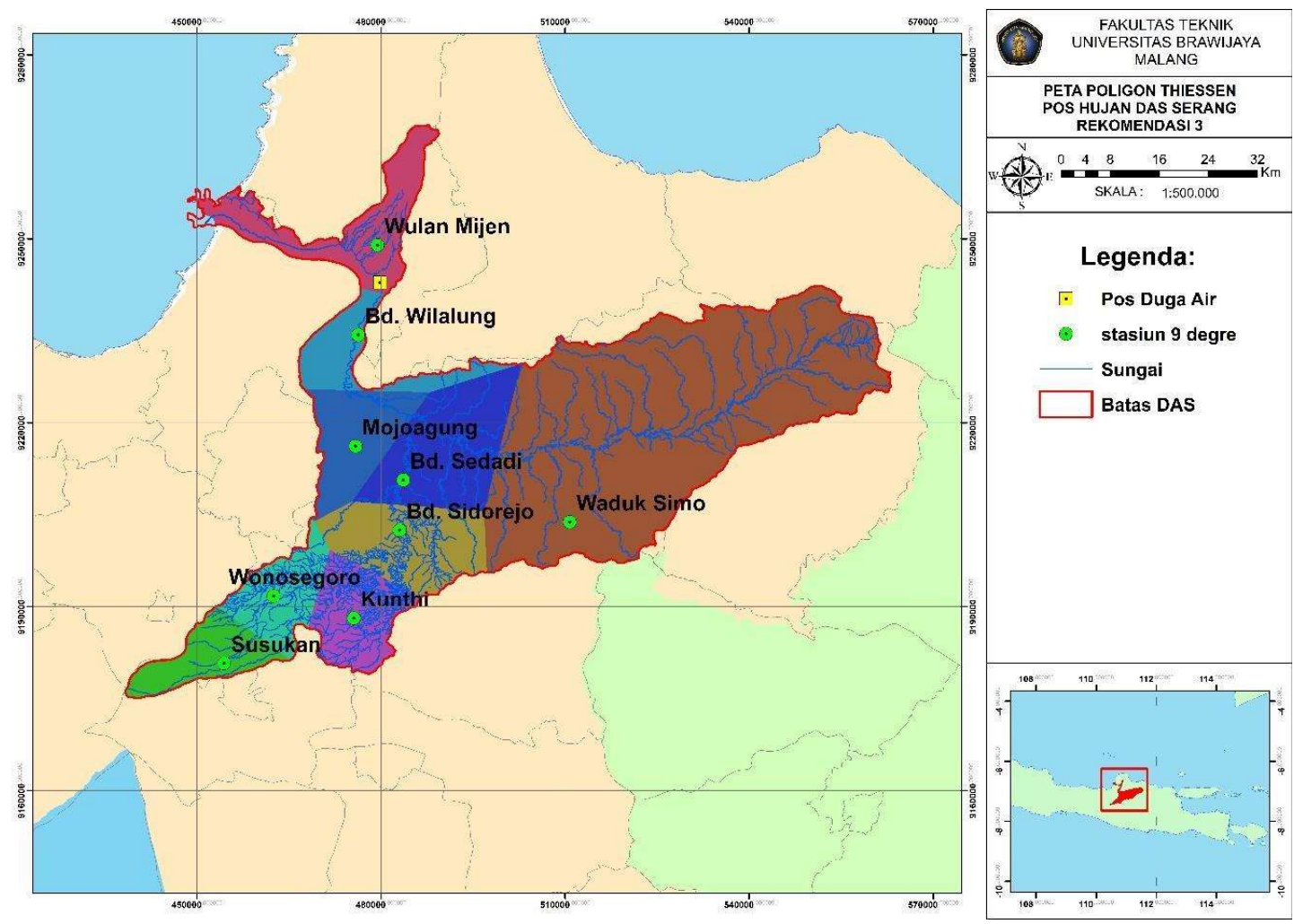

Gambar 3. Peta Polygon Thiessen stasiun hujan eksisting DAS Serang

Tabel 5. Hubungan luas daerah pengaruh dengan kriteria standar WMO (eksisting)

\begin{tabular}{clcccc}
\hline No & $\begin{array}{c}\text { Nama Stasiun } \\
\text { Hujan }\end{array}$ & $\begin{array}{c}\text { Luas Daerah } \\
\text { Pengaruh } \\
\mathrm{km}^{2}\end{array}$ & $\begin{array}{c}\text { Koefisien } \\
\text { Thiessen }\end{array}$ & $\begin{array}{c}\text { Prosentase } \\
(\%)\end{array}$ & $\begin{array}{c}\text { Luas Daerah }\left(\mathrm{km}^{2}\right) \text { per satu } \\
\text { pos hujan ideal }(300-1000) \\
\mathrm{km}^{2}\end{array}$ \\
\hline 1 & Bd. Sidorejo & 300.39 & 0.086 & 8.63 & ideal \\
\hline 2 & Kunti & 1730.95 & 0.498 & 49.75 & tidak \\
\hline 3 & Mojoagung & 291.13 & 0.084 & 8.37 & tidak \\
\hline 4 & Susukan & 227.68 & 0.065 & 6.54 & tidak \\
\hline 5 & Bd. Wilalung & 214.73 & 0.062 & 6.17 & tidak \\
\hline 6 & Wulan Mijen & 183.47 & 0.053 & 5.27 & tidak \\
\hline 7 & Bd. Sedadi & 164.59 & 0.047 & 4.73 & tidak \\
\hline 8 & Wonosegoro & 366.13 & 0.105 & 10.52 & tidak \\
\hline 9 & Wd. Simo & 169.44 & 0.049 & 4.87 & \\
\hline & Jumlah & 3479.08 & 1.000 & 100 & \\
\hline
\end{tabular}

Rekomendasi II ditunjukkan pada Gambar 5, di mana stasiun yang luas daerahnya tidak memenuhi kriteria WMO dihilangkan, sehingga jumlah stasiun yang awalnya ada sembilan stasiun mejadi enam stasiun saja. Dari Tabel 7 yang merupakan hasil analisa dari Gambar 5, dapat dilihat bahwa tiga stasiun eksisting yang luas daerahnya tidak memenuhi kriteria WMO (St. Wonosegoro, St. Mojoangung dan St. Bd. Sedadi) dihilangkan untuk memenuhi persyaratan luas daerah yang ideal.

Rekomendasi III ditunjukkan pada Gambar 6, di mana luasan daerah cakupan tiap-tiap stasiun hujan setelah dilakukan penggeseran tanpa mengurangi jumlah stasiun eksisting didapat lebih merata serta memenuhi standar WMO. 
Karena stasiun hujan merupakan aset negara yang berharga, maka opsi penghilangan stasiun tidak begitu dianjurkan, maka diajukan Rekomendasi III dengan cara menggeser stasiun-stasiun yang ada sehingga luas daerah pengaruh memenuhi standar WMO.

Tabel 8 menunjukkan luas daerah pengaruh sesuai dengan Rekomendasi III setelah dilakukan beberapa penggeseran. Tabel tersebut menunjukkan jumlah stasiun eksisting dan luasan daerah pengaruhnya setelah dilakukan penggeseran lokasi setiap stasiun hujan memiliki luasan cakupan yang ideal (300 - $1000 \mathrm{~km}^{2}$ per 1 pos hujan).

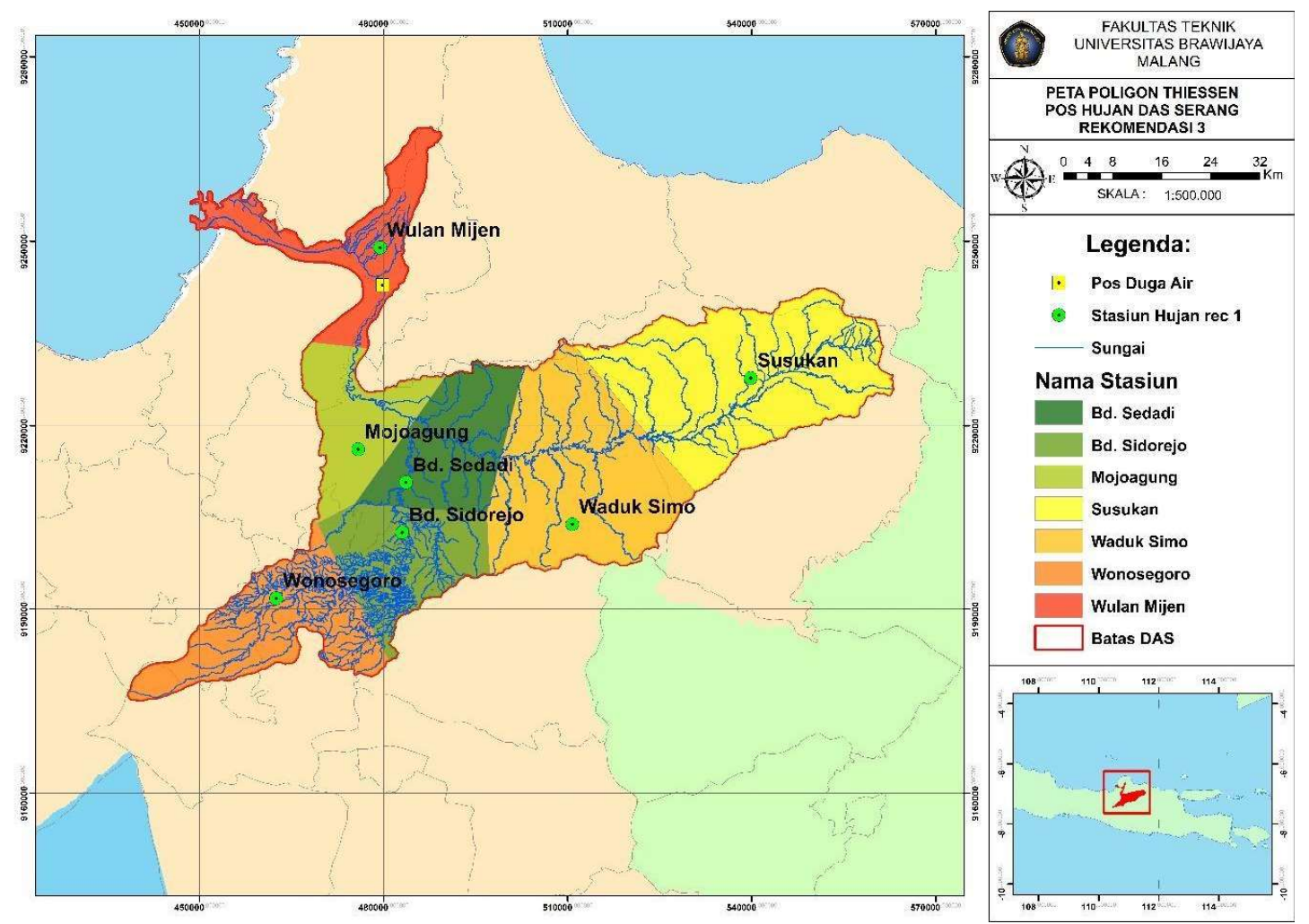

Gambar 4. Peta Polygon Thiessen stasiun hujan DAS Serang Rekomendasi I

Tabel 6. Luas daerah pengaruh stasiun hujan Rekomendasi I pada DAS Serang (tujuh pos hujan)

\begin{tabular}{clcccc}
\hline No & $\begin{array}{c}\text { Nama } \\
\text { Stasiun } \\
\text { Hujan }\end{array}$ & $\begin{array}{c}\text { Luas Daerah } \\
\text { Pengaruh } \\
\mathrm{km}^{2}\end{array}$ & $\begin{array}{c}\text { Koefisien } \\
\text { Thiessen }\end{array}$ & $\begin{array}{c}\text { Prosentase } \\
(\%)\end{array}$ & $\begin{array}{c}\text { Luas Daerah }\left(\mathrm{km}^{2}\right) \text { per satu } \\
\text { pos hujan ideal } \\
(300-1000) \mathrm{km}^{2}\end{array}$ \\
\hline 1 & Bd. Sidorejo & 391.11 & 0.107 & 10.720 & ideal \\
\hline 2 & Wd. Simo & 915.72 & 0.251 & 25.098 & ideal \\
\hline 3 & Wulan Mijen & 342.29 & 0.094 & 9.382 & ideal \\
\hline 4 & Mojoagung & 321.00 & 0.088 & 8.798 & ideal \\
\hline 5 & Kunthi & 476.91 & 0.131 & 13.071 & ideal \\
\hline 6 & Susukan & 386.38 & 0.106 & 10.590 & ideal \\
\hline 7 & Bd. Sedadi & 815.12 & 0.223 & 22.341 & ideal \\
\hline & Jumlah & 3648.52 & 1.00 & 100.00 & \\
\hline
\end{tabular}




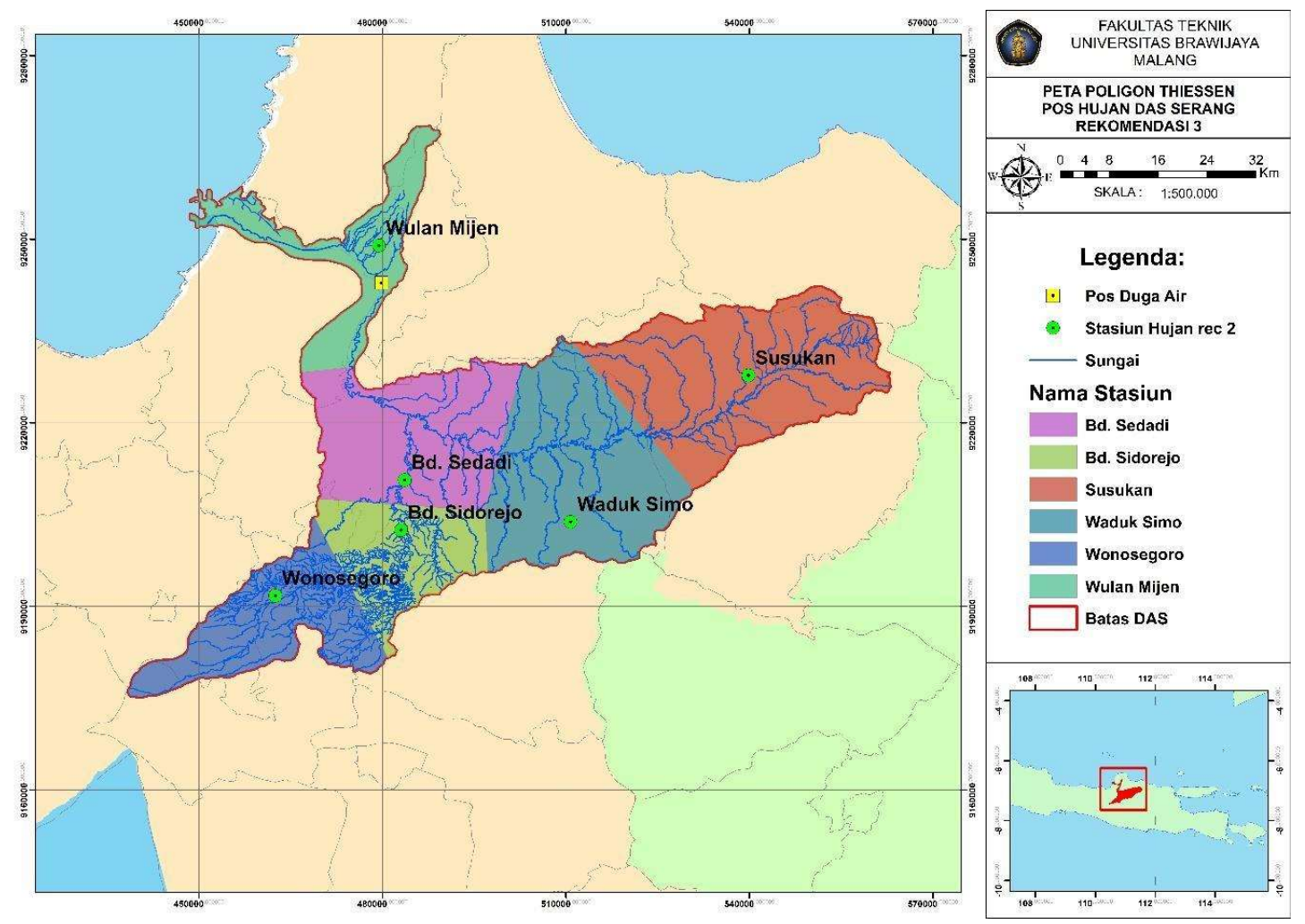

Gambar 5. Peta Polygon Thiessen stasiun hujan DAS Serang Rekomendasi II

Tabel 7. Luas daerah pengaruh stasiun hujan Rekomendasi II pada DAS Serang (enam pos hujan)

\begin{tabular}{clcccc}
\hline No & $\begin{array}{c}\text { Nama Stasiun } \\
\text { Hujan }\end{array}$ & $\begin{array}{c}\text { Luas Daerah } \\
\text { Pengaruh } \\
\mathrm{km}^{2}\end{array}$ & $\begin{array}{c}\text { Koefisien } \\
\text { Thiessen }\end{array}$ & $\begin{array}{c}\text { Prosentase } \\
(\%)\end{array}$ & $\begin{array}{c}\text { Luas Daerah }\left(\mathrm{km}^{2}\right) \text { per satu } \\
\text { pos hujan ideal } \\
(300-1000) \mathrm{km}^{2}\end{array}$ \\
\hline 1 & Bd. Sidorejo & 659.07 & 0.181 & 18.064 & ideal \\
\hline 2 & Wd. Simo & 915.72 & 0.251 & 25.098 & ideal \\
\hline 3 & Wulan Mijen & 384.38 & 0.105 & 10.535 & ideal \\
\hline 4 & Kunthi & 477.09 & 0.131 & 13.076 & ideal \\
\hline 5 & Susukan & 397.14 & 0.109 & 10.885 & ideal \\
\hline 6 & Bd. sedadi & 815.12 & 0.223 & 22.341 & ideal \\
\hline & Jumlah & 3648.52 & 1.00 & 100.00 & \\
\hline
\end{tabular}




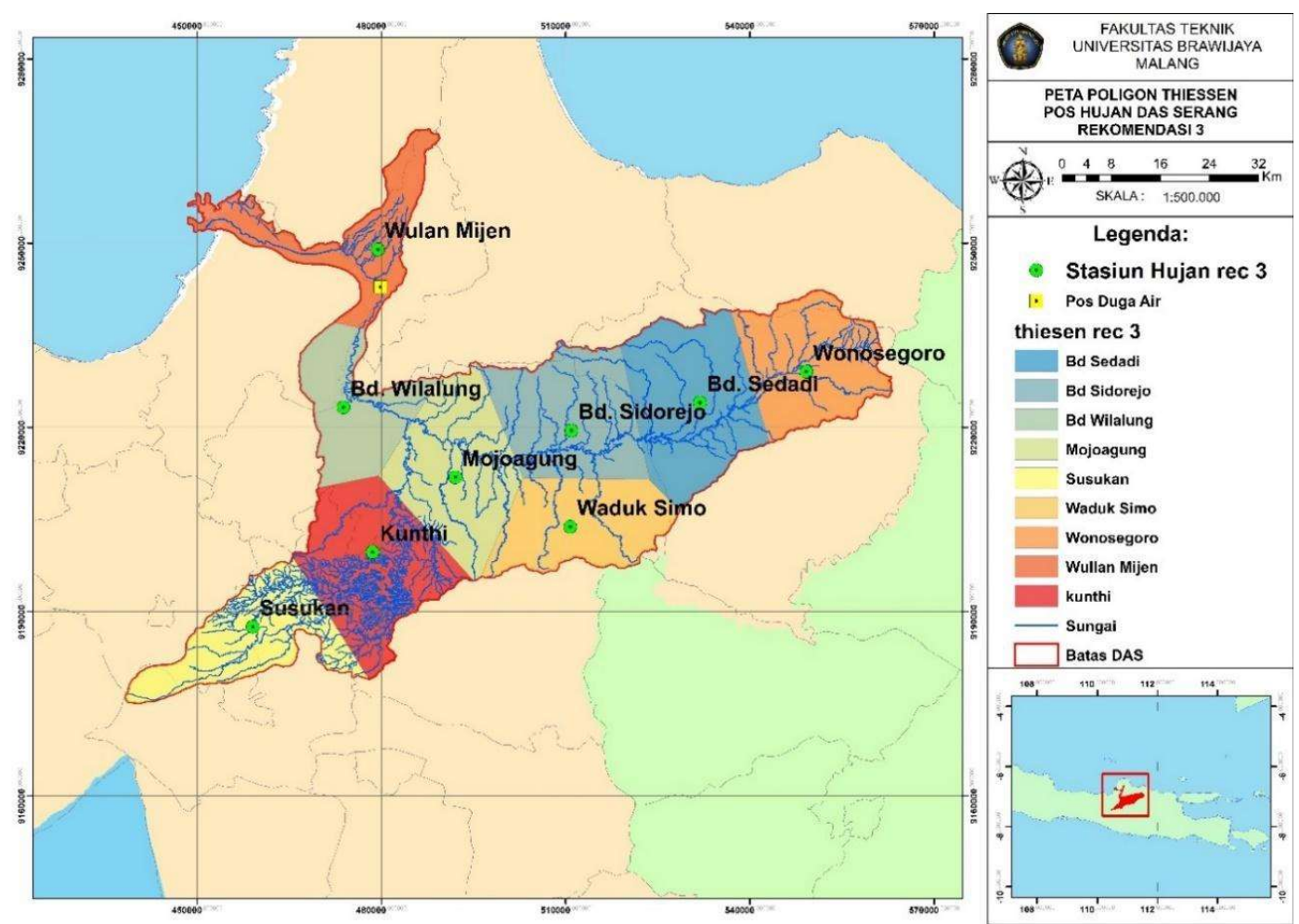

Gambar 6. Peta Polygon Thiessen stasiun hujan DAS Serang Rekomendasi III

Tabel 8. Luas daerah pengaruh stasiun hujan Rekomendasi III pada DAS Serang (sembilan pos hujan)

\begin{tabular}{clcccc}
\hline No & $\begin{array}{c}\text { Nama Stasiun } \\
\text { Hujan }\end{array}$ & $\begin{array}{c}\text { Luas Daerah } \\
\text { Pengaruh } \mathrm{km}^{2}\end{array}$ & $\begin{array}{c}\text { Koefisien } \\
\text { Thiessen }\end{array}$ & $\begin{array}{c}\text { Prosentase } \\
(\%)\end{array}$ & $\begin{array}{c}\text { Luas Daerah }\left(\mathrm{km}^{2}\right) \text { per satu } \\
\text { pos hujan ideal } \\
(300-1000) \mathrm{km}^{2}\end{array}$ \\
\hline 1 & Bd. Sidorejo & 438.383 & 0.120 & 12.02 & ideal \\
\hline 2 & Kunti & 489.069 & 0.134 & 13.41 & ideal \\
\hline 3 & Mojoagung & 457.941 & 0.126 & 12.55 & ideal \\
\hline 4 & Susukan & 362.081 & 0.099 & 9.93 & ideal \\
\hline 5 & Bd. Wilalung & 311.153 & 0.085 & 8.53 & ideal \\
\hline 6 & Wulan Mijen & 315.311 & 0.086 & 8.64 & ideal \\
\hline 7 & Bd. Sedadi & 502.802 & 0.138 & 13.78 & ideal \\
\hline 8 & Wonosegoro & 403.997 & 0.111 & 11.08 & ideal \\
\hline 9 & Wd. Simo & 366.778 & 0.101 & 10.06 & \\
\hline & Jumlah & 3647.515 & 1.000 & 100 &
\end{tabular}

\section{Kesimpulan}

Hasil sebaran stasiun hujan berdasar metode Stepwise dan metode Kriging sudah merata, hal ini ditunjukkan dengan hasil analisa $R$ untuk metode Stepwise yang mendekati 1 (hubungan antar stasiun sangat kuat) dan nilai RMSE untuk metode Kriging yang kecil.

Dari hasil analisis evaluasi sebaran stasiun hujan yang dilakukan dengan metode Stepwise dan Kriging didapat bahwa sebaran stasiun hujan di DAS Serang tidak memenuhi standar WMO (untuk daerah pegunungan tropis berkisar antara $300-1000 \mathrm{~km}^{2}$ per satu pos hujan). Setelah dilakukan analisa yang mengacu pada Standar WMO untuk luas cakupan tiap-tiap stasiun hujan (untuk Indonesia berkisar $300-1000 \mathrm{~km}^{2}$ per satu stasiun), didapatkan dua rekomendasi sebaran stasiun hujan yang didapat, yaitu; Rekomendasi I yang berjumlah tujuh stasiun hujan dan Rekomendasi II 
yang berjumlah enam stasiun dengan perlakuan yang sama dengan Rekomendasi I. Namun karena stasiun hujan adalah aset negara yang berharga, maka opsi penghilangan stasiun tidak begitu dianjurkan, maka diajukan Rekomendasi III dengan cara menggeser stasiun-stasiun yang ada tanpa menghilangkan stasiun yang sudah ada (tetap sembilan stasiun) sehingga luas daerah pengaruh memenuhi standar WMO.

\section{Saran}

Pada peneliti selanjutnya agar menggunakan variasi metode yang beragam dalam perhitungan parameter hidrologi yang sekiranya dapat mempengaruhi perencanaan jaringan stasiun hujan untuk mengevaluasi kerapatan dan pola sebaran stasiun hujan pada DAS Serang, serta SNI untuk pola sebaran dan pembangunan stasiun hujan di Indonesia juga perlu dipertimbangkan.

\section{Daftar Pustaka}

Adhikary, Sajal Kumar, Nitin Muttil, and Abdullah Gokhan Yilmaz. 2018. "Improving Streamflow Forecast Using Optimal Rain Gauge Network-Based Input to Artificial Neural Network Models." Hydrology Research 49(5).

Andiego, George, Muhammad Waseem, Muhammad Usman, and Nithish Mani. 2018. "The Influence of Rain Gauge Network Density on the Performance of a Hydrological Model." Computational Water, Energy, and Environmental Engineering 8(1).

Gourley, Jonathan J., and Baxter E. Vieux. 2005. "A Method for Evaluating the Accuracy of Quantitative Precipitation Estimates from a Hydrologic Modeling Perspective." Journal of Hydrometeorology 6(2): 115-33.

Hadihardaja, Iwan K., and Sugeng Sutikno. 2005. "Pemodelan Curah Hujan-Limpasan Menggunakan Artificial Neural Network (ANN) Dengan Metode Backpropagation." Jurnal Teknik Sipil 12(4).

Kar, Anil Kumar, A. K. Lohani, N. K. Goel, and G. P. Roy. 2015. "Rain Gauge Network Design for Flood Forecasting Using Multi-Criteria Decision Analysis and Clustering Techniques in Lower Mahanadi River Basin, India.” Journal of Hydrology: Regional Studies 4: 313-32.

Montesarchio, Valeria et al. 2015. "Evaluation of Optimal Rain Gauge Network Density for Rainfall-Runoff Modelling." AIP Conference Proceedings 1648(1). https://aip.scitation.org/doi/abs/10.1063/1.4912473.

Sri Harto. 1993. Analisis Hidrologi. Gramedia Pustaka Utama.

Takeda, Kensaku, and Suyono Sosrodarsono. 2003. PT Pradnya Paramita Hidrologi Untuk Pengairan. Jakarta: PT Pradnya Paramita.

Triatmodjo, Bambang. 2010. Beta Offset Hidrologi Terapan. Yogyakarta: Beta Offset. 